Juan Acacio y Gabriela Wyczykier, Expectativas públicas y conflictos sociales en torno a los hidrocarburos no convencionales en Argentina: algunos apuntes sobre Vaca Muerta, Izquierdas, 49, abril 2020: 457-477

\title{
Expectativas públicas y conflictos sociales en torno a los hidrocarburos no convencionales en Argentina: algunos apuntes sobre Vaca Muerta
}

Public expectations and social conflicts around unconventional hydrocarbons in Argentina: some notes about Vaca Muerta

\author{
Juan Acacio* \\ Gabriela Wyczykier**
}

\begin{abstract}
Resumen: En el presente escrito se analizan algunas dimensiones relacionadas con las implicancias de la producción de energía extrema en la formación geológica de Vaca Muerta, en particular en la Provincia de Neuquén, a través de la utilización de la técnica del fracking. Para ello, partimos de un presupuesto de intelección general: la cuestión energética puede ser analizada como un sistema donde los distintos actores se encuentran en permanente tensión y disputa por un recurso que es vital para la producción económica y para satisfacer las condiciones de bienestar de la población, pero resulta apropiado de forma asimétrica. Asimismo, la extracción y producción de energía se desenvuelve en distintos territorios y los impactos socioambientales, políticos y económicos se distribuyen de forma desigual y problemática. Con esta finalidad el escrito se organiza a partir de dos niveles de indagación: 1) "desde arriba", la concepción del megaproyecto de Vaca Muerta como política pública de gobierno, centralmente desde 2012 en adelante, advirtiendo continuidades y rupturas en las propuestas, programas y concepciones oficiales respecto de su explotación y 2) "desde abajo", dando cuenta de los atributos y particularidades de los actores colectivos y de la conflictividad social que se ha generado en torno a este proceso extractivo.
\end{abstract}

Palabras clave: Energía extrema; Vaca Muerta; Neuquén; Política pública; Conflictos sociales

\begin{abstract}
In this paper we analyze some dimensions related to the implications of the production of extreme energy in the geological formation of Vaca Muerta, in particular in the Province of Neuquén, through the use of the fracking technique. For this, we start from a general intellection budget: the energy issue can be analyzed as a system where the different actors are in constant tension and dispute for a resource that is vital for economic production and to satisfy the welfare conditions of the population, but it is appropriate asymmetrically. Likewise, the extraction and production of energy takes place in different territories and the socio-environmental, political and economic impacts are distributed unevenly and problematically. With this purpose we will organize the writing from two levels of inquiry: 1) "from above", the conception of the Vaca Muerta megaproject as a public policy of government, centrally from 2012 onwards, warning continuities and ruptures in the proposals, programs and official conceptions regarding
\end{abstract}

\footnotetext{
${ }^{*}$ Argentino, coautor, becario doctoral CONICET, con sede de trabajo en el Instituto de Investigación en Historia y Ciencias Sociales (IdIHCS-CONICET). acaciojuan89@gmail.com

** Argentina, coautora, investigadora y docente de la Universidad Nacional de General Sarmiento y del CONICET, gwyczykier@yahoo.com
} 
Juan Acacio y Gabriela Wyczykier, Expectativas públicas y conflictos sociales en torno a los hidrocarburos no convencionales en Argentina: algunos apuntes sobre Vaca Muerta, Izquierdas, 49, abril 2020: 457-477

their exploitation and 2) "from below", giving an account of the attributes and particularities of the collective actors and of the social conflicts that have arisen around this extractive process.

Keyword: Extreme energy; Vaca Muerta; Neuquén; Public policy; Social conflicts

Recibido: 9 noviembre 2018 Aceptado: 17 febrero 2019

\section{Introducción $^{1}$}

En el mes de abril de 2018 retornó ávidamente a la agenda pública en la Argentina la cuestión del "tarifazo" en los servicios públicos esenciales². En este marco, el presidente Mauricio Macri eligió la provincia de Neuquén, donde se ubica la mayor parte del megaproyecto extractivo de Vaca Muerta, para trasmitir y confirmar sobre la base de dogmas neoliberales la inevitabilidad de los aumentos sobre la energía.

Los funcionarios del gobierno reafirmaban así la inexistencia de opciones. Tanto para el oficialismo como para la oposición la cuestión giró en torno al precio de la energía y a los subsidios energéticos, que aparecían como un factor crítico para las cuentas fiscales del país. Esto obturó una reflexión multidimensional sobre la energía, considerando que, en el proceso de su producción y explotación, las poblaciones resultan diversamente afectadas.

En el presente escrito partimos de un presupuesto de intelección general: la cuestión energética requiere ser analizada como un entramado de relaciones de poder, donde los distintos actores se encuentran en permanente tensión y disputa por un recurso que es vital para la producción económica y para satisfacer las condiciones de bienestar de la población, pero resulta apropiado de forma asimétrica. Asimismo, la extracción y producción de energía se desenvuelve en distintos territorios y los impactos socioambientales, políticos y económicos se distribuyen de forma desigual y problemática. Como destaca Bertinat (2015), la cuestión energética requiere ser tratada no solamente observando la producción y consumo de determinados volúmenes físicos, sino que debe incluirse a las políticas públicas, los conflictos sectoriales, las alianzas geopolíticas, las estrategias empresariales, los desarrollos tecnológicos, la diversificación productiva, el tipo de lógica empresarial que caracteriza al sistema, la relación entre energía y distribución de la riqueza, entre energía y matriz productiva, y las relaciones con la tecnología, entre otros elementos a considerar.

Con esta perspectiva nos interesa reflexionar sobre algunas dimensiones relacionadas con el megaproyecto Vaca Muerta, tanto por su relevancia geopolítica y nacional, como por sus impactos económicos, sociales y simbólicos. Efectivamente, para los gobiernos de Cristina F. de Kirchner (20072015) y de Mauricio Macri (desde diciembre 2015) la explotación de hidrocarburos no convencionales aparece como una potencial salida de la crisis energética, y como un negocio económico productivo de gran envergadura. $\mathrm{Al}$ mismo tiempo, su explotación cristaliza una etapa societal en la que se produce "energía extrema", que refiere no sólo a las características de los hidrocarburos no convencionales, sino a un contexto en el cual la explotación supone un incremento en los riesgos geológicos, ambientales, laborales y sociales (Roa Avendaño y Scandizzo, 2016). Esto ha gestado como contrapartida

${ }_{1}$ Un análisis preliminar de la información propuesta en este artículo fue presentado en las VIII Jornadas de Historia de la Patagonia, Viedma, octubre 2018.

2 El tarifazo fue un proceso ligado a una serie de medidas impuestas por parte del gobierno nacional que implicaron un aumento en las facturas del servicio público del gas, y que tuvo como contrapartida la gestación de acciones de protesta durante el 2016, acontecidas en distintas zonas del territorio nacional, llevadas adelante por usuarios residenciales y sector productivo. 
Juan Acacio y Gabriela Wyczykier, Expectativas públicas y conflictos sociales en torno a los hidrocarburos no convencionales en Argentina: algunos apuntes sobre Vaca Muerta, Izquierdas, 49, abril 2020: 457-477

movimientos de resistencia contra el fracking, técnica privilegiada para la apropiación del recurso, impulsados por distintos sectores de la sociedad en el ámbito local especialmente.

Nuestro objetivo es profundizar en las implicancias que tiene la producción de energía extrema en el territorio considerando 1) "desde arriba", la concepción del megaproyecto de Vaca Muerta como política pública de gobierno, centralmente desde 2012 en adelante, advirtiendo continuidades y rupturas en las propuestas, programas y concepciones oficiales respecto de su explotación y 2) "desde abajo", dando cuenta de los atributos y particularidades de los actores colectivos, y de la conflictividad social que se ha generado en torno a este proceso extractivo.

El trabajo se desarrolló a partir de una metodología cualitativa de investigación social, articulando el estudio de un conjunto de fuentes de información: análisis de entrevistas en profundidad realizadas a informantes calificados ${ }^{3}$, declaraciones públicas de organizaciones y partidos políticos, lectura de informes sectoriales, notas periodísticas y análisis de legislaciones ${ }^{4}$.

\section{Sobre el neoextractivismo y la producción de energías extremas}

En los últimos 150 años la generación de energía ha estado basada en la explotación de combustibles fósiles. A nivel global, el $81 \%$ de la energía proviene del gas, el petróleo y el carbón (Observatorio Petrolero Sur y Eduardo D`Elia, 2014).

En este contexto, diversos autores y actores colectivos sostienen que nos enfrentamos por tanto al colapso de la civilización industrial, y el declive de los recursos hidrocarburíferos pone en jaque todo el funcionamiento del aparato productivo industrializado y de los servicios: "El desarrollo de las fuerzas productivas auspiciados por el funcionamiento del capital, y posibilitadas por los combustibles fósiles, ha implicado cada vez más el desarrollo de las fuerzas destructivas del metabolismo urbano agro industrial". En consecuencia, asistimos a una etapa de desarrollo del capital donde se combinan la crisis energética, el cambio climático y el colapso ecológico global, todos ellos en íntima y recíproca relación. Los problemas ecológicos actuales debemos contemplarlos, en definitiva, desde una perspectiva que se concentre en el análisis de la lógica del poder (Durán, 2011, p. 15).

Ciertamente, en las postrimerías del siglo XX y los inicios del XXI adquirió fuerza un diagnóstico compartido: nos encontramos ante una situación de crisis climática y energética mundial que plantea la necesidad de una transición hacia fuentes renovables, y hacia una desfosilización de las matrices energéticas. Ello sitúa a los diferentes actores en el campo económico, público, comunitario, social y científico ante un escenario complejo. Así, las desigualdades y asimetrías tanto en relación con el impacto del cambio climático como en el poder sobre los bienes primarios utilizados para la provisión del consumo energético, generan conflictos territoriales a niveles nacionales, regionales y globales.

En este escenario, como señalan Gudynas y Honty (2014), el uso creciente de recursos hidrocarburíferos aumenta la emisión de gases nocivos para el medio ambiente. Pero aún más, el descubrimiento y explotación de las reservas de recursos de gas y petróleo no convencional interfieren sobre el entramado de relaciones sociales, de dominación y desigualdad entre grupos sociales ${ }^{5}$. En este

\footnotetext{
3 Para este artículo se introdujeron testimonios de 8 entrevistas en profundidad, realizadas en el mes de abril de 2018, en la ciudad de Neuquén.

${ }_{4} \mathrm{La}$ investigación se inscribe en el proyecto "La energía como problemática integral: Escenarios, geopolítica y transiciones. Una aproximación comparativa e interdisciplinaria al caso argentino", financiado por la Agencia Nacional de Promoción Científica y Tecnológica, Argentina.

${ }^{5} \mathrm{El}$ extractivismo se refiere a las actividades que remueven grandes volúmenes de recursos naturales que no son procesados (o que lo son limitadamente), orientados especialmente hacia la exportación. Esta modalidad productiva, cabe destacar, no se limita a los minerales o al petróleo, sino que se aprecia en actividades vinculadas al extractivismo agrario, forestal y pesquero (Acosta, 2012). En esta dirección, Gudynas y Honty (2014) distinguen la extensión de procesos extractivistas de tercera y cuarta generación en la región latinoamericana. Entre los primeros, mencionan actividades como la de la minería a cielo
} 
sentido, los gobiernos latinoamericanos, alentados por una creciente demanda de consumo interno e internacional de bienes primarios producidos bajo una lógica extractivista, favorecen la amplificación de efectos críticos por sus consecuencias eco y socio ambientales.

La producción de energía extrema se encuentra por lo tanto relacionada con la ampliación del extractivismo o neoextractivismo, de consecuencias inéditas en los territorios. Como destaca Svampa (2016), el extractivismo actual refiere a un patrón de acumulación basado en la sobre explotación de bienes naturales a gran escala, vehiculizado mayormente por mega emprendimientos que implican significativas inversiones monetarias, con actores transnacionalizados que suelen resultar capitales intensivos. Al mismo tiempo, la apropiación y disposición territorial afecta concomitantemente otras actividades productivas favoreciendo en consecuencia el desarrollo de enclaves económicos.

El acceso a hidrocarburos no convencionales que ha permitido el avance tecnológico de la fractura hidráulica (fracking) responde así a una nueva fase de relacionamiento social, político, ambiental, económico y territorial, con la producción de energía extrema con atributos de una dinámica neoextractivista: una modalidad privilegiada por actores económicos y públicos de incentivar la acumulación de capital por un lado y, por el otro, de los estados nacionales de satisfacer el consumo de energía doméstica y como recurso exportable.

Como destacan Roa Avedaño y Scandizzo (2017), ante la premura del fin de la extracción de hidrocarburos de fácil acceso, empresas y gobiernos se han lanzado a las formaciones sedimentarias compactas, los crudos pesados, extra-pesados, y las arenas bituminosas, en formaciones geológicas donde los hidrocarburos requieren técnicas y procesos de extracción más costosos y complejos con grandes impactos socio ambientales. Esta modalidad de explotación avanza sobre territorios campesinos, de pueblos originarios y sobre otras matrices productivas locales y regionales.

Estas condiciones colocan en el centro del debate el uso de una técnica controversial para acceder a los recursos no convencionales, como así también la modalidad de consumo energético predominante en las distintas economías. En el caso de la Argentina, se aprecia una matriz energética altamente dependiente de los combustibles fósiles, entre ellos del gas y el petróleo. Según datos sistematizados por Pablo Bertinat en base al Balance Energético Nacional del Ministerio de Energía y Minería de la Nación, hacia el año 2016 la producción de energía primaria estaba representada en un $53 \%$ por el gas natural, un $36 \%$ por petróleo, y un 5\% proveniente de la energía hidráulica.

En este escenario y en el marco de la imposibilidad de los gobiernos recientes de Argentina de procurarse el autoabastecimiento de recursos energéticos y tener por tanto que recurrir a la importación de los mismos, el descubrimiento del potencial de hidrocarburos no convencionales de la formación geológica Vaca Muerta inauguró una nueva etapa en la producción y proyección de energía en el país.

\section{El fracking en debate}

El descubrimiento del shale gas en 2010 en la Argentina habilitó oficialmente la etapa de los hidrocarburos no convencionales, a partir de la perforación realizada por la empresa YPF-Repsol en el yacimiento Loma la Lata. Si bien el conocimiento de la existencia de estos recursos se remonta a décadas atrás, tanto los precios como la tecnología disponible en ese entonces no permitieron la extracción de este tipo de recursos.

En el año 2005 había comenzado a desarrollarse el shale en Estados Unidos, mientras que en 2011 la Asociación Internacional de Energía publicó un informe sobre la existencia de estos recursos a nivel global, incluyendo a la Argentina entre los países con disponibilidad de este bien (Di Sbroiavacca,

abierto, la perforación petrolera, la expansión de monocultivos, mientras denominan extractivismo de cuarta generación a la extracción de hidrocarburos no convencionales. Para un debate más extenso sobre el extractivismo ver el trabajo de Juan Grigera y Laura Álvarez, "Extractivismo y acumulación por desposesión. Un análisis de las explicaciones sobre agronegocios, megaminería y territorio en la Argentina de la posconvertibilidad.”. En Theomai, año 2013. 
Juan Acacio y Gabriela Wyczykier, Expectativas públicas y conflictos sociales en torno a los hidrocarburos no convencionales en Argentina: algunos apuntes sobre Vaca Muerta, Izquierdas, 49, abril 2020: 457-477

2013). De acuerdo a la Energy Information Adminstration (EIA) en la actualidad existen cuatro países con volúmenes de producción comercial de shale gas y shale oil: Estados Unidos, Canadá, China y Argentina, ubicándose este último en el segundo puesto mundial con mayores recursos de shale gas, y en cuarto puesto con recursos de shale oil (Romero, Mastrinardi, Villa Martínez, 2017).

Los hidrocarburos no convencionales no son distintos a los convencionales, ya que su génesis es la misma, aunque difiere en su ubicación geológica. En efecto, los hidrocarburos han estado alojados por siglos en rocas madres, pero migraron, dando lugar a que una parte de estos recursos más ligeros emergieran de la roca generadora y se desplazaran hacia capas superiores, permitiendo su extracción desde los inicios del siglo XIX. Sin embargo, muchos de estos hidrocarburos continuaron presos en las rocas generadoras sin poder migrar, resultando más dificultosa su explotación con las técnicas habitualmente utilizadas en la industria petrolera. Allí se encuentran los denominados hidrocarburos no convencionales, cuya característica distintiva es su baja permeabilidad: el shale gas/oil, y el tight gas/oil (gas y petróleo) (Gómez Jiménez, D; Sans Oliva, J; y Portero Larragueta, J. 2014).

El fracking permitió, en consecuencia, el acceso a los hidrocarburos no convencionales a través de la perforación de pozos dirigidos que pueden seguir una dirección no solo vertical sino también horizontal. A diferencia de los convencionales, la vida útil de estos pozos suele ser mucho menor, y poseen una marcada caída de su producción luego de los primeros años. Para realizar la perforación de la roca se inyectan grandes volúmenes de agua, con una presión muy elevada, utilizando arenas y productos químicos. ${ }^{6} \mathrm{El}$ aprovechamiento de esta técnica supone un importante desarrollo industrial, causando un efecto significativo sobre los espacios donde se asienta. Cada plataforma puede incluir hasta 24 pozos, requiriendo una extensión geográfica de relevancia, lo que implica una ocupación intensiva del territorio (Gómez Jiménez, D; Sans Oliva, J; y Portero Larragueta, J. 2014).

La fractura hidráulica resulta una técnica controversial dado que los fluidos que se inyectan pueden comunicarse con las napas de agua dulce, o bien con la superficie (D Elía y Ochandio, 2014). La inadecuada cementación de los pozos puede generar, por tanto, efectos ambientales de magnitud, cuestión también presente en las perforaciones de pozos convencionales, pero que resulta aún de mayor significación, dada la cantidad de perforaciones que exigen los no convencionales, las grandes presiones de agua utilizadas, y el desarrollo rápido y exponencial de estas técnicas donde aún no se advierte el desarrollo de prácticas seguras (Gómez Jiménez, D; Sans Oliva, J; y Portero Larragueta, J. 2014).

En efecto, diversos estudios realizados en países como Estados Unidos y otras geografías muestran evidencias respecto de los daños que esta técnica de perforación ocasiona en el ecosistema y en las poblaciones ligadas directa e indirectamente con esta actividad. Entre algunos hallazgos, se advierte sobre la contaminación de aire y las fuentes de agua potable, los problemas de salud y seguridad ocupacional que se refleja en muertes, enfermedades y accidentes ocurridos a trabajadores ligados a la actividad hidrocarburífera; el gas natural extraído de los pozos genera por otra parte efectos climáticos de magnitud por la liberación de metano en el ambiente; la infraestructura desplegada para el fracking ocasiona asimismo consecuencias perniciosas para las condiciones de vida de las poblaciones que habitan en zonas cercanas al despliegue de la actividad. Otros efectos tienen que ver con un incremento notable en la contaminación acústica, lumínica y un aumento en el estrés de la población, sobre todo de los trabajadores vinculados a la producción. Existen también otras cuestiones, como el peligro que la actividad del fracking representa para las tierras destinadas a la producción agrícola y ganadera, así como también el potencial peligro de emisiones radioactivas en el proceso extractivo,

\footnotetext{
${ }^{6}$ En general el fluido está compuesto en un 90\% de agua, 9\% de arenas tratadas para mantener abierta la fractura, y alrededor de un $1 \%$ de aditivos químicos. Estos últimos, a presar de ser proporcionalmente bajos, son los responsables de la efectividad última de la mezcla y de la potencial peligrosidad del fluido para el medio ambiente. Además, se utilizan ácidos previa estimulación para disolver posibles obstrucciones en la formación geológica (Gómez Jiménez, D; Sans Oliva, J; y Portero Larragueta, J. 2014).
} 
Juan Acacio y Gabriela Wyczykier, Expectativas públicas y conflictos sociales en torno a los hidrocarburos no convencionales en Argentina: algunos apuntes sobre Vaca Muerta, Izquierdas, 49, abril 2020: 457-477

debido a los insumos necesarios para el proceso de perforado (Concerned Health Proffesionals of NY, et al., 2015).

\section{Vaca Muerta y la expectativa pública de autoabastecimiento energético.}

\section{La balanza energética deficitaria: la génesis de un problema político.}

Luego del descubrimiento en 2010 del shale gas en la formación geológica de Vaca Muerta ${ }^{7}$ se inauguró un período de transformaciones políticas, sociales y regulatorias de impacto nacional y subnacional, en el marco de una profunda situación de crisis de abastecimiento de la energía destinada al consumo interno. La restricción externa de la balanza de pagos resultó un problema de suma importancia política durante el segundo gobierno de Cristina F. de Kirchner. El crecimiento de la demanda doméstica no solamente implicó por tanto contar con menos volúmenes de recursos para poder exportar, sino además derivó en el incremento de las importaciones, lo que trajo aparejado un fuerte impacto en el sector energético. De esta manera, mientras en 2004 existía un "superávit" que alcanzaba 17,5 Millones m3/día, a partir de 2008 el balance se convirtió en negativo y en 2014 las importaciones superaron a las exportaciones en 32,5 Millones m3/día (Gil, Govorani, y Codeseira, 2015).

Ello contrasta claramente con la potencialidad de autoabastecimiento que se constató en el país en décadas precedentes, y que comenzó a revertirse con el proceso de reestructuración de la economía y de privatización de empresas públicas llevado adelante en la década del 90. Durante gran parte de los gobiernos kirchneristas, las empresas trasnacionales ligadas a la producción hidrocarburífera tendieron a concentrar mayoritariamente sus inversiones en el recurso más rentable (el petróleo) y a relegar el gas natural. El legado crítico generado por las reformas estructurales y la lógica de comportamiento del oligopolio energético asociado a él no fue revertido sino profundizado en base a un mercado que jurídica y económicamente operaba con escasas limitaciones. En consecuencia, el gasto público destinado al sector energético fue creciendo de manera exponencial durante el período 2003-2014. En su conjunto, este sector explicó el 27,1\% del crecimiento del gasto público. Al limitar el análisis al período 2012-2014, se distingue que este gasto fue el que más contribuyó a este crecimiento con un $59,9 \%$, seguido muy de lejos por el destinado a seguridad social (13,1\%) (Goldstein, Kulfas, Margulis, y Zack, 2016).

En este contexto se produjo el hallazgo de los recursos no convencionales, y la riqueza de la formación Vaca Muerta fue advertida por funcionarios nacionales y provinciales como un salvamento en varios sentidos: para reimpulsar la producción de hidrocarburos en vistas de lograr el autoabastecimiento energético; como proyecto de desarrollo económico productivo que permitiera la creación de empleo y el aumento de los recursos monetarios; y como un esquema de negocios que atrajera las inversiones extranjeras directas al territorio nacional.

\section{Vaca Muerta y la esperanza pública}

Con este espíritu, en el año 2012 se sancionó la ley de soberanía hidrocarburífera (Ley $\mathrm{N}^{\circ}$ 26.741) cuyo planteo principal estribó en la expropiación del 51\% de las acciones de YPF y en la

\footnotetext{
7 La cuenca neuquina abarca 120.000 kilómetros cuadrados mayormente de Neuquén, una parte de Mendoza, La Pampa y Río Negro. La extensión de la formación Vaca Muerta ocupa unos $30.000 \mathrm{~km}$, la gran parte en superficie neuquina, aunque también una porción se ubica en el sur mendocino y también en el oeste de Río Negro. Al mismo tiempo, en casi toda la cuenca neuquina hay otras formaciones no convencionales explotables mediante la técnica del fracking, como Agrio y Los Molles, también de shale o esquisto, y Mulichinco y Las Lajas, de tight o arcillas compactas (https://www.lanacion.com.ar/1785554-vaca-muerta-quienes-son-los-duenos-del-yacimiento)
} 
Juan Acacio y Gabriela Wyczykier, Expectativas públicas y conflictos sociales en torno a los hidrocarburos no convencionales en Argentina: algunos apuntes sobre Vaca Muerta, Izquierdas, 49, abril 2020: 457-477

promoción de la explotación masiva de los no convencionales como medio para lograr el autoabastecimiento. Pero además resultó un mecanismo que aspiraba a traccionar al conjunto de la producción, impulsando el desarrollo de empresas que proveyeran insumos y servicios para la explotación, a fin de lograr saldos exportables para equilibrar la balanza de pagos y obtener divisas (OPSur y D Elía, 2014). Estos objetivos fueron inicialmente planteados por el flamante CEO de la nueva YPF, Miguel Galuccio, que aspiraba a convertir al país en exportador neto de energía (Gallegos, 2015).

Ello ganó impulso con la sanción, por parte de la legislatura de la provincia de Neuquén, de la Ley Provincial 2867 el 29 de agosto de 2013, que ratificaba el acuerdo que el Poder Ejecutivo local había firmado un mes atrás con YPF para llevar adelante un proyecto piloto en Vaca Muerta en asociación con la empresa multinacional Chevron. Este acuerdo controvertido fue votado mientras se reprimía a las organizaciones sociales que se manifestaban en contra de su sanción, tanto por la existencia de denuncias contra la empresa trasnacional ${ }^{8}$, como también por la localización de este proyecto en territorio comunitario mapuche del lof Campo Maripe, sin el consentimiento de los afectados directos. Se incumplía así con tratados internacionales, como el convenio 169 de la OIT, que regulan la actividad en territorios comunitarios, y que establecen, entre otras cosas, los mecanismos de consulta. Los legisladores que aprobaron el proyecto sostuvieron una posición favorable por la urgencia de sustituir la importación de energía (Giuliani, 2017)..$^{10}$

El acuerdo de YPF y Chevron en las áreas Loma Campana y Loma La Lata Norte permitió a la empresa ser la única que encaró un desarrollo masivo en Vaca Muerta. En el 2014 la Argentina ya se había constituido en uno de los cuatro únicos países del mundo con explotación comercial de hidrocarburos de esquisto del mundo, junto con Estados Unidos, Canadá y China. YPF totalizaba en ese entonces el $86 \%$ de los 361 pozos perforados, $91 \%$ de la producción petrolera y $89 \%$ de la de gas en la formación (Rebossio, 2015).

Con el fin de recuperar el autoabastecimiento energético y revertir el balance productivo negativo, el Estado Nacional trasfirió ingresos a las empresas petroleras en calidad de subsidios. Del 2013 al 2015, estos superaron los 3000 millones de dólares anuales (cifra similar al gasto nacional en Salud y casi tres veces el gasto en Ciencia). Estos subsidios tendieron a premiar la exploración y el incremento de las inversiones tanto de la explotación convencional, como de la no convencional. La inversión productiva de las empresas creció logrando aumentos del empleo, mientras los niveles de producción lograron revertir un ciclo de caída constante ${ }^{11}$ (Zanotti, Kofman, López Crespo y Chemes, 2017).

Con el arribo de la coalición de Cambiemos al gobierno en diciembre de 2015, la política de subsidios al sector energético fue ajustada con urgencia fiscalista, produciéndose una transferencia

\footnotetext{
8 YPF y Chevron lograron que Neuquén les extendiera la concesión de Loma Campana y Loma La Lata hasta 2048. Para obtener los primeros 1.240 millones de dólares provistos por la multinacional, el Gobierno firmó un decreto que le permite a las petroleras que inviertan más de mil millones de dólares exportar, a partir de los cinco primeros años, un $20 \%$ de lo que produzca sin límites de retención. El decreto garantizaba, además, la libre disponibilidad de las divisas. Esta empresa extranjera había sido por otra parte, condenada en Ecuador por la contaminación de unas 500.000 hectáreas en la Amazonía que afectó a unos 30.000 integrantes de las comunidades aborígenes de la región (Peregil, 2013). (https://elpais.com/economia/2013/07/17/actualidad/1374017376_300532.html)

${ }_{9}$ La palabra lof designa a la unidad organizacional básica del pueblo mapuche.

${ }^{10} \mathrm{La}$ propiedad de los hidrocarburos parte de la definición del art. $1^{\circ}$ de la ley que declara a los yacimientos de hidrocarburos líquidos y gaseosos de propiedad inalienable e imprescriptible del Estado nacional. Luego de la reforma constitucional de 1994, esa propiedad corresponde a la provincia o a la Nación, dependiendo del lugar en que se encuentre el yacimiento. Las reservas de hidrocarburos no pertenecen a la empresa que los explota, sino al Estado. La propiedad del bien se adquiere en algún momento dentro del período desde que son extraídos del yacimiento en la profundidad de la tierra hasta que se toma posesión de ellos en la superficie. En el caso del gas, la propiedad se adquiere en la cabeza del pozo, o sea, al traspasar la válvula de salida. Es en ese punto donde puede ejercerse físicamente la posesión efectiva, y no antes (IEPAC, 2014).

${ }^{11} \mathrm{El}$ 8\% de la matriz energética nacional depende de la importación de combustibles fósiles (FARN, 2018).
} 
Juan Acacio y Gabriela Wyczykier, Expectativas públicas y conflictos sociales en torno a los hidrocarburos no convencionales en Argentina: algunos apuntes sobre Vaca Muerta, Izquierdas, 49, abril 2020: 457-477

directa de recursos hacia las empresas a través del aumento de tarifas a los consumidores. Ciertamente, en ambos ciclos políticos las empresas vieron favorecida su rentabilidad gracias a la política de subsidios del Estado que les aseguró un precio ventajoso abonando con recursos públicos la diferencia entre lo cobrado a través de las tarifas y la extracción en boca de pozo según valor de mercado internacional, con la diferencia que en la administración actual se acrecentó el peso de esta diferencia en las facturas de servicios de los usuarios.

La política de subsidios hacia las empresas continuó por lo tanto durante los primeros años de la flamante nueva gestión, pero desarmando principalmente el Plan Gas destinado a la producción de gas natural convencional y asegurando la continuidad hasta 2021 principalmente del Plan Gas para Vaca Muerta y otras formaciones no convencionales en la Cuenca Neuquina (García Zanotti, Kofman, López Crespo y Chemes, 2017) ${ }^{12}$.

La orientación pública con relación a la explotación de los recursos no convencionales en Vaca Muerta resulta por tanto una de las políticas públicas que muestra continuidades con referencia a la expectativa de autoabastecimiento energético, de estimular el desarrollo productivo y de contribuir con las exportaciones. Las palabras del CEO de YPF durante el segundo gobierno de Cristina F. de Kirchner sostenían en esta dirección:

"Hay que poner en valor el no convencional, que tiene un potencial impresionante. Los fundamentos de la demanda de petróleo no cambiaron. Tanto China como India, siguen siendo motores fundamentales de desarrollo, siguen con el mismo futuro que tenían. Y en esos países hay un montón de gente que va a depender del hidrocarburo, y va a seguir siendo importante para el mundo (la energía renovable al 2040) va a representar el $15 \%$ de la matriz energética y el 85 por ciento va a seguir siendo de hidrocarburos" (Declaraciones de Gallucio, M., 2 de diciembre de 2014).

La posición del gobierno de Cambiemos profundizaba en similar dirección:

"Hoy al mirar este lugar lo que vemos es desarrollo es movimiento, es producción, es empleo, es crecimiento para los neuquinos y para todos los argentinos, es energía para poner en marcha los hogares, las fábricas, las empresas y los comercios. Gracias a lo bien que vamos con el proceso de desarrollo de Vaca Muerta y otras formaciones rocosas y las energías renovables nos estamos preparando para ser grandes productores de gas." (Discurso de Mauricio Macri en la formación Vaca Muerta, Neuquén, 23 de abril de 2018).

La manera de contribuir al desarrollo del sector de hidrocarburos en relación con la política de subsidios resulta tal vez la de mayor distinción entre ambos gobiernos, considerando que Cambiemos priorizó una orientación que restó intermediación al Estado en relación con el consumo interno de gas y petróleo, con excepción del Plan Gas prorrogado para los no convencionales.

Las palabras del ex ministro de energía de Macri así lo distinguían:

"Queremos que el mercado se comporte como tal. El Gobierno ya ha hecho mucho: eliminamos las retenciones a las exportaciones y quitamos los aranceles a las importaciones. Con eso quitamos la variable de tener precios artificiales en la Argentina, que, como consecuencia de eso, estamos donde

\footnotetext{
12 En el artículo 1ª de la Resolución 46-E/2017, el Ministerio de Energía y Minería de la Nación creaba el "Programa de Estímulo a las Inversiones en Desarrollos de Producción de Gas Natural proveniente de Reservorios No Convencionales", destinado a incentivar las inversiones para la producción de gas natural proveniente de reservorios de estas características en la Cuenca Neuquina.

El Plan Gas había sido creado en el año 2013 durante el segundo gobierno de Cristina F. de Kirchner, con fecha de finalización el 31 de marzo de 2017. Esta herramienta tenía como objetivo incentivar la producción de gas natural subsidiando el precio de boca de pozo a fin de revertir el déficit en la balanza de pagos y el energético.
} 
Juan Acacio y Gabriela Wyczykier, Expectativas públicas y conflictos sociales en torno a los hidrocarburos no convencionales en Argentina: algunos apuntes sobre Vaca Muerta, Izquierdas, 49, abril 2020: 457-477

estamos, hay que aprender. Por haber intervenido mucho en los mercados hoy tenemos que importar el 25\% del gas y el 10\% del crudo liviano que necesitamos" (Entrevista realizada por Penelli, D., a J. J. Aranguren, 9 de noviembre de 2017) ${ }^{13}$

Funcionarios del gobierno de Cambiemos vinculados al sector energético se han mostrado conjuntamente proclives a la explotación y aprovechamiento de los hidrocarburos no convencionales, incluso como modalidad de complementar un proceso de transición hacia las energías renovables. José Luis Sureda, ex secretario de Hidrocarburos y número dos del ex ministro de energía José Aranguren aseguraba al respecto:

"En la Argentina disponemos de mucho más gas natural que el que podemos consumir a lo largo de la transición hacia las energías renovables, por más larga que esta sea. Los recursos gasíferos no convencionales, que solo en nombre de la brevedad sintetizaremos en Vaca Muerta, permiten afirmar que se trata de un recurso infinito. Sin dudas, el gas natural debe ser nuestro carrier. Y también podemos contribuir al proceso de transición global, exportando carrier. El desarrollo económico de esta enorme dotación del recurso gas puede constituirse en una verdadera palanca de transformación económica y social para nuestro país" (19 de marzo de 2018) ${ }^{14}$

La apuesta pública por Vaca Muerta resultó por tanto acentuada durante la gestión del ex ministro de energía José Aranguren. La extensión de subsidios a las empresas que apostaran a estos yacimientos fue una de estas variables mientras la reforma laboral promovida por el gobierno para los trabajadores petroleros en el 2017 fue otra de las modalidades de incentivar la inversión en el megaproyecto. En efecto, los cambios producidos en el convenio laboral en acuerdo con el sindicato del sector implicaron una baja en los costos para las empresas y una pérdida de beneficios para los trabajadores.

Asimismo, este acuerdo entre el sindicato del sector y las autoridades públicas resultó profundizado con la firma de un "blindaje" para Vaca Muerta en octubre 2018, cuando representantes de la Unión Obrera de la Construcción de la República Argentina -UOCRA - junto a dirigentes petroleros, firmó un acuerdo en el que se comprometen a no realizar medidas de fuerza de carácter nacional o provincial. ${ }^{15}$ Las medidas acordadas con los sectores del trabajo y los empresarios tradujeron por lo tanto el apremio del Poder Ejecutivo para motorizar este mega emprendimiento hidrocarburífero:

"El objetivo estratégico es reemplazar las importaciones. Al importar, importamos mano de obra extranjera, impuestos y regalías que se pagan afuera. Si lo reemplazamos por producción propia tendríamos mano de obra local, factor multiplicador en la economía, pago de impuestos y regalías, desarrollo económico. El desarrollo de Vaca Muerta genera condiciones para poder reemplazar la importación. Si le quieren llamar autoabastecimiento, llámenle autoabastecimiento" (Entrevista realizada a J. J. Aranguren por Penelli, D, 9 de noviembre de 2017) ${ }^{16}$

La Argentina sin embargo se encuentra lejos del autoabastecimiento energético tan preciado por los funcionarios públicos. En el caso del petróleo no se ha logrado revertir su tendencia productiva negativa. El balance 2017 arrojó como resultado que este recurso estaba por debajo de los niveles

\footnotetext{
13http://www.ambito.com/902977-el-autoabastecimiento-energetico-no-es-una-condicion-isine-qua-noni-para-tenerdesarrollo-economico

14 https://econojournal.com.ar/2018/03/el-futuro-de-la-energia-vaca-muerta-como-puente-hacia-las-renovables/

15 Un análisis reciente sobre el "blindaje" de Vaca Muerta y sus efectos políticos y sociales se encuentra en Svampa, Maristella: https://www.elcohetealaluna.com/author/maristella-svampa/

16http://www.ambito.com/902977-el-autoabastecimiento-energetico-no-es-una-condicion-isine-qua-noni-para-tener-

desarrollo-economico
} 
Juan Acacio y Gabriela Wyczykier, Expectativas públicas y conflictos sociales en torno a los hidrocarburos no convencionales en Argentina: algunos apuntes sobre Vaca Muerta, Izquierdas, 49, abril 2020: 457-477

productivos de 1980, traduciendo 19 años de caída desde su récord en 1998, en gran medida por la baja inversión en pozos convencionales. La producción promedio de petróleo estuvo un $6 \%$ por debajo de la de 2016, mientras que la producción de gas disminuyó un 0,6\%. En este último caso, la caída en la producción de gas convencional es considerada en el sector una consecuencia de la política oficial al discontinuar el Plan Gas proveniente de la administración del kirchnerismo, mientras el ex ministro de energía, José Aranguren, prometía como contrapartida premiar la producción de gas no convencional (Bidegaray, 2018). ${ }^{17}$

Durante el 2018 la producción de petróleo en el país tuvo una sensible recuperación de un 2\% en relación al año anterior, mientras que en el caso del gas se constató un incremento del 5,3\% vinculado con la explotación de no convencionales del área Fortín de Piedra de Vaca Muerta, impulsado por el subsidio a este tipo de hidrocarburo que aseguraba un precio de u\$s7,50 por millón de BTU, donde el Estado cubre la diferencia entre ese valor y el que percibe la empresa que vende el recurso en el mercado local (Peco, Silvina, 2019).

Desde el arribo del gobierno de Macri la importación de petróleo creció en consecuencia un $26 \%$. Por lo tanto, al cabo de casi dos años ya se había importado un tercio de todo el crudo importado entre 2008 y 2015. Al comparar los tramos enero-noviembre del primer año de gestión con el segundo 2017- las compras de petróleo extranjero crecieron aún más: 33,8\% (Penelli, 2018), mientras que la importación de metros cúbicos de naftas y gasoil en el primer semestre 2018 aumentó 13,48\% (Ámbito, 3 de agosto 2018). ${ }^{18}$

Ello sin embargo no invalida la promoción pública de Vaca Muerta que se constata en diferentes aspectos. La información provista por el Ministerio de Energía permite observar que, mientras en el 2012 la producción de gas natural convencional en términos proporcionales era del $97,12 \%$, y la de no convencionales resultaba del 2,86\%, en el 2016, y con un descenso regular, los convencionales aportaron el 78,66\% de este hidrocarburo, mientras lo no convencionales lo hicieron en un 21,34\%. Con relación a la producción de petróleo, se advierte que en 2012 los convencionales aportaron el 99,37\% contra un $0,63 \%$ de los no convencionales, y en el 2016, luego de un descenso sostenido en términos relativos de los convencionales, éstos aportaron el 93,22\% y los no convencionales, en progresivo ascenso, el 6,78\%. Los niveles de inversión en estos recursos han sido ascendentes, y ello se observa en el aumento de la producción de pozos no convencionales: en el 2012 eran 109 (casi enteramente de tight gas, solo dos de shale gas), y en el 2016 ascendieron a 706 (638 de tight gas y 38 de shale gas) (Romero, Mastrinardi, Vila Martínez, 2017). ${ }^{19}$ En ascenso, en el 2018 la producción total de gas no convencional creció $7,1 \%$ interanual hacia julio, acumulando un 5,1\% en los primeros siete meses de ese año. El shale gas, en efecto, se incrementó en un $192 \%$ en julio contra igual mes del año anterior (El Economista, 22 de febrero 2018). ${ }^{20}$

\section{Vaca Muerta desde abajo: el territorio neuquino en disputa}

La explotación de hidrocarburos, la riqueza, los dilemas y conflictos que ésta conlleva en términos políticos, sociales, económicos y ambientales permea sustancialmente la historia de la provincia de

\footnotetext{
17 https://www.clarin.com/economia/produccion-petrolera-cayo-peores-anos_0

18 https://www.ambito.com/energia-celebra-mas-produccion-gas-y-petroleo-hacienda-lamenta-mas-importacioncombustibles-n4029551

19 YPF dispone, por intermedio de su subsidiaria Y-Sur, un 32,6\% de las tierras concesionadas para su explotación en Vaca Muerta; Total - firma de origen francés - dispone de un 13,1\% del territorio. En el tercer puesto se ubica Pampa Energía, petrolera del Grupo Mindlin posee un 12,2\% de la superficie de la formación, mientras que en cuarto y quinto lugar se posicionan Pluspetrol, con un 8,2\%, y Oilstone, con un 5,1 por ciento. El 28,8\% restante se distribuye entre otras 12 organizaciones, como Exxon, Shell, Chevron y el Grupo Techint (8 de marzo de 2017, https://www.infobae.com/economia/2017/03/08/tres-petroleras-concentran-la-operatoria-en-vaca-muerta)

20 https://www.eleconomista.com.ar/2018-09-los-no-convencionales-son-la-gran-apuesta-a-mediano-plazo/
} 
Juan Acacio y Gabriela Wyczykier, Expectativas públicas y conflictos sociales en torno a los hidrocarburos no convencionales en Argentina: algunos apuntes sobre Vaca Muerta, Izquierdas, 49, abril 2020: 457-477

Neuquén. ${ }^{21}$ Esto se debe a los rendimientos monetarios que percibe la provincia por la propiedad de los recursos, sobre todo en concepto de regalías ${ }^{22}$, así como a los beneficios en términos de aumento del producto bruto interno en relación al desarrollo de actividades vinculadas a la explotación del petróleo y el gas. Sin embargo, la actividad hidrocarburífera colisiona con otras actividades y con distintos grupos sociales que habitan y reproducen sus condiciones de existencia material, social y cultural allí donde se desenvuelve la explotación y la producción de energía proveniente de fuentes fósiles.

La explotación de hidrocarburos no convencionales en Vaca Muerta adquirió la forma de un megaproyecto de grandes dimensiones y con diversas connotaciones. Como bien establecen Álvarez, Mullally, et al. (2017) definirlo como megaproyecto implica pensarlo según ciertas características: a) La cadena de valor se organiza desde procesos anteriores a la perforación hasta la refinería, pasando por ductos, insumos específicos para cada etapa y culminando en plantas tratadoras de residuos; b) Con referencia a la infraestructura actual y proyectada se distingue el despliegue de caminos, viviendas, servicios, y la reorganización de pueblos y ciudades; c) Se articulan alrededor del megaproyecto una multiplicidad de empresas que cuentan cada una de ellas con su respectiva arquitectura financiera y contractual, donde existen radicaciones societarias en diversos puntos del planeta, incluidos distintos paraísos fiscales y jurídicos. Por lo tanto, la dimensión geográfica de Vaca Muerta supera los 30.000 km2 de la formación geológica, y en Argentina abarca seis provincias en forma directa, como Neuquén, Río Negro, Mendoza, Chubut, Buenos Aires y Entre Ríos.

Otro elemento de relevancia es la creciente articulación entre sector público y privado para la explotación de los no convencionales, que tomó envión a partir de la expropiación parcial de YPF en el 2012, otorgando al Estado una función doble: por un lado, como el principal operador y conductor en el desarrollo y, por el otro, como generador de condiciones de posibilidad, regulando las políticas del sector y promoviendo su competitividad. La potencialidad de expansión del megaproyecto ha sido favorecida por una cultura e historia provincial ligada a una tradición petrolera y a una perspectiva productivista del desarrollo atada a los hidrocarburos (Álvarez Mullally, et al., 2017).

En efecto, como destaca Scandizzo (2016) fue en los años 90 cuando se consolidó la importancia de los hidrocarburos en la economía neuquina. Ello se debió al descubrimiento de nuevos yacimientos, al aumento de las exportaciones de estos recursos y al incremento de las regalías. Como contrapartida, el costo de aquel dinamismo resultó en una rápida disminución de las reservas de gas y petróleo, y la provincia experimentó un descenso sostenido entre 1999 y 2006 en su extracción. Entre 2007 y el 2015, producto del desacople del precio del barril interno del internacional reglamentado por el Ministerio de Economía, se generó una disminución en las regalías que pasaron de constituir el 46\% del total de ingresos corrientes en 2007, al 28\% en 2011. El gobierno de Sapag 23 promovió entonces un plan de diversificación productiva, expresado en el Plan Productivo Provincial (2009-2018) para fomentar el desarrollo agroindustrial, si bien no claudicó del incentivo del sector hidrocarburífero. Para ello, creó en 2008 la sociedad anónima Gas y Petróleo del Neuquén por considerarlo un vector fundamental del modelo productivo. El descubrimiento y posibilidad de explotación de hidrocarburos no convencionales en Vaca Muerta vitalizó la proyección productiva de estos recursos, tornándose nuevamente central en las aspiraciones políticas de los dirigentes.

El impacto de la actividad hidrocarburífera convencional y no convencional en el territorio ha sido significativa: a) generó una gran concentración de la economía en torno a estas actividades, siendo

${ }_{21}$ Con respecto a los no convencionales, en el 2016 el 99, 84\% provino de la cuenca neuquina (Romero, C., Mastrinardi, L., Villa Martínez, J.P., 2017)

22 La distribución de la renta fruto de la explotación de los recursos naturales en un país puede analizarse a través del ingreso que obtienen por su contribución al PBI, a las inversiones y a las exportaciones y a los ingresos fiscales. En América Latina, las regalías y los impuestos a la renta son los más significativos en términos de públicos. Las primeras representan la participación del Estado en la propiedad de los recursos (Claudia, V. y Cruzado, E., 2012)

23 2007-2015 
Juan Acacio y Gabriela Wyczykier, Expectativas públicas y conflictos sociales en torno a los hidrocarburos no convencionales en Argentina: algunos apuntes sobre Vaca Muerta, Izquierdas, 49, abril 2020: 457-477

éste un sector con baja demanda de mano de obra en términos relativos, y operando el empleo público como integrador sociolaboral24; b) ocasionó desequilibrios salariales, ya que las remuneraciones de los trabajadores petroleros son superiores a los ingresos salariales promedio de la provincia, gestando como efecto la distorsión del mercado inmobiliario y aumentando los precios domésticos de bienes y servicios, contribuyendo de este modo a la profundización de la desigualdad social; c) desplazó actividades productivas con las cuáles la explotación petrolera compite por recursos, como el agua, la energía, y la tierra; observado ello con respecto a la ganadería, la agricultura, y el turismo; d) se advierten impactos ambientales ${ }^{25}$ ligados a la utilización de la técnica del fracking 26 ; e) se generalizaron las adicciones como el alcoholismo, el juego, y las drogas, que suelen afectar a los trabajadores petroleros, amplificándose además los riesgos de accidentes y la vulnerabilidad laboral (Svampa y OPSur, 2014; Giuliani, 2017).

Ante el avance del megaproyecto Vaca Muerta, distintas organizaciones y actores sociales locales han visualizado y resistido de distintos modos, y por variados motivos, la producción de energía extrema en el territorio.

\section{Conflictos y disputas en torno al fracking: el territorio en tensión}

Como ya mencionamos anteriormente, en el año 2013 la empresa YPF se asoció con la multinacional Chevron para la explotación conjunta de la formación de Vaca Muerta en la provincia de Neuquén. Al tener la provincia la potestad sobre los recursos hidrocarburíferos, la legislatura neuquina debía ratificar este acuerdo. Este hecho encontró a una multitud movilizada en contra de esta asociación.

En esta movilización confluyó no sólo una crítica a la técnica del fracking, sino que se enlazó además con otros elementos. El rechazo fue orientado principalmente a la presencia de Chevron, por ser una empresa controvertida a nivel internacional, y por ingresar al territorio mediante un contrato con apartados confidenciales, que no dejaba en claro cuál sería el rol de la empresa estadounidense, ni bajo qué condiciones ambas empresas se vinculaban. Todo ello se combinó con la crítica a una situación económica provincial que contrastaba con las promesas de derrame económico y bienestar que la nueva actividad prometía.

La movilización estuvo convocada y encabezada por la Multisectorial Contra la Hidrofractura y por la Asamblea Permanente del Comahue por el Agua (APCA). También coincidieron en ella sindicatos, como la Asociación de Trabajadores del Estado (ATE) y el combativo gremio de docentes: la Asociación de Trabajadores de la Educación de Neuquén (ATEN). Como bien indica Melé (2016) esta movilización puede ser leída como la construcción de una red híbrida que implicó la alianza y la movilización de sectores heterogéneos: vecinos, actores políticos, sectores ambientalistas, sindicales, y organizaciones mapuches.

Tanto APCA como la Multisectorial contra la Hidrofractura eran colectivos que se encontraban organizados con anterioridad a la firma del contrato YPF-Chevron. En el año 2012 se conformó APCA, que estaba integrada, como menciona Riffo (2016), por el Observatorio Petrolero Sur, la

${ }^{24}$ El empleo público excede la media nacional rondando el 30\% (Giuliani, 2017). De acuerdo con un informe elaborado por el Ministerio de Producción y de Energía y Minería, El megaproyecto Vaca Muerta empleaba en total 454.000 puestos de trabajo en 2017 entre empleos directos e indirectos promovidos por la actividad: 247.000 trabajadores realizaban tareas de exploración y producción de hidrocarburos, 72.000 en el transporte, refinación del petróleo, regasificación, comercialización y distribución de gas, y 135.000 empleos estaban asociados a la actividad (Spaltro, Santiago, 2018) (www.cronista.com/economiapolitica/Vaca-Muerta-milagrosa-prometen-crear-100-mil-nuevos-empleos-en-un-ano-201809170088.html)

25 En el mes de octubre de 2018 ocurrió un derrame de petróleo en la formación Vaca Muerta, a solamente 11 km de la localidad de Añelo, que afectó en principio 45 hectáreas.

26 Para una mayor descripción de los riesgos ambientales de los no convencionales y el fracking ver: Álvarez Mullally, et al., (2017). Disponible en: http://ejes.org.ar/InformeExternalidades.pdf 
Juan Acacio y Gabriela Wyczykier, Expectativas públicas y conflictos sociales en torno a los hidrocarburos no convencionales en Argentina: algunos apuntes sobre Vaca Muerta, Izquierdas, 49, abril 2020: 457-477

Confederación Mapuche de Neuquén, La Fundación Ecosur - Patagonia Norte, y la Corriente de Organizaciones de Base La Brecha, junto con ciudadanos no agrupados. Ya en el año 2011 APCA organizaba actividades de difusión sobre la técnica del fracking, y denunciaba los pasivos ambientales que generaba la actividad hidrocarburífera (Álvarez y Gutiérrez, 2016). Distintas organizaciones se encontraban en estado de alerta y denunciaban al Estado provincial por encubrir los peligros de la actividad no convencional. En declaraciones públicas APCA, junto a distintos colectivos de las provincias de Río Negro y Neuquén, establecían:

"La preocupación por la grave crisis ambiental que atenta contra la salud pública de toda la población de la biorregión patagónica, afecta la vida y pone en riesgo mortal la producción de alimentos que es básica para el desarrollo de la vida más allá de la extinción de los combustibles fósiles". (Declaraciones de la Jornada de capacitación y asamblea resolutiva de vecinos y organizaciones ante la grave crisis ambiental en las cuencas de la región norpatagónica. Allen, 27 de octubre de 2012).

En su diagnóstico, los colectivos se manifestaban en contra del avance de la explotación petrolera y vinculaban su lucha con otras resistencias ambientales, como respecto de la megaminería, en defensa del agua y de la vida. Asimismo, demandaban la expulsión de las empresas que se encontraban explotando recursos fósiles en la localidad de Allen, en la provincia de Río Negro, dedicada tradicionalmente a la fruticultura. Asimismo, expresaban su solidaridad con las comunidades mapuches en territorios afectados por la explotación petrolera. En las declaraciones del encuentro citado se remarcaba la necesidad de pensar en la diversificación de las actividades productivas de la región problematizando la matriz energética existente, y apostando a la búsqueda de alternativas renovables.

En el año 2013 se organizó la Multisectorial contra la Hidrofractura, un espacio que se desprende y se diferencia de APCA. Aunque no muestran diferencias en sus programas, ni en sus diagnósticos sobre la situación que atraviesa la provincia de Neuquén, APCA adquirió dinámicas más vinculadas a la tradición de asambleas ciudadanas surgidas luego del conflicto contra la megaminería en Esquel en el año 2003, así como también de las experiencias de Catamarca y La Rioja (Álvarez y Gutiérrez, 2016) y contra las pasteras en Gualeguaychú, nucleándose a nivel nacional en la Unidad de Asambleas Ciudadanas (UAC). Dicho formato de organización tiene su correlato con la multiplicidad de organizaciones barriales y asambleas populares autoconvocadas surgidas al calor de la crisis de la convertibilidad en el año 2001. Como bien destaca Svampa (2006) estos formatos de organización y acción colectiva presentan dinámicas particulares, ya que significan el territorio como espacio de disputa y resistencia, adoptan medidas de acción directas no tradicionales, desarrollan formas de democracia directa, y mantienen una pretensión de autonomía con respecto a partidos políticos y otros espacios organizados.

La Multisectorial, a diferencia de APCA, se construyó entonces como un espacio donde tenían un lugar preponderante las organizaciones. ${ }^{27}$ Uno de nuestros entrevistados señalaba: "La Multisectorial no niega los sindicatos, no niega los partidos políticos, no niega las organizaciones feministas, no niega las organizaciones estudiantiles, a las organizaciones barriales." (Entrevista $\mathrm{n}^{\circ} 1$ realizada por autor a referente de la Comunidad Mapuche de Neuquén en abril de 2018).

Lo que menciona el entrevistado no es una cuestión de poca relevancia. Como bien marca Riffo (2016), existe una tensión entre los espacios asamblearios ciudadanos y los espacios que ya se encontraban previamente organizados. Mientras las asambleas priorizan la participación individual en calidad de "ciudadanos/as", las organizaciones poseen tiempos distintos, ya que precisan de un espacio de debate colectivo previo para la toma de decisiones. De esta manera, el desencuentro con las

27 La Multisectorial se encuentra conformada actualmente por el Observatorio Petrolero Sur, la Confederación Mapuche de Neuquén, Tierra Para Vivir -Comahue, Emancipación Sur- Neuquén, Unidad Popular, ATE (áreas protegidas), la Colectiva Feminista la Revuelta, el Movimiento Socialista de los Trabajadores, y Patria Grande (Riffo, 2016). 
Juan Acacio y Gabriela Wyczykier, Expectativas públicas y conflictos sociales en torno a los hidrocarburos no convencionales en Argentina: algunos apuntes sobre Vaca Muerta, Izquierdas, 49, abril 2020: 457-477

asambleas se relaciona con la siguiente observación de un entrevistado: "(muchas veces) pretenden despojar a las personas de cualquier otra particularidad que no sea la de ciudadano unipersonal, manifestando su voluntad y su ideología particular." (Entrevista $n^{\circ} 1$ realizada por autor a referente de la Confederación Mapuche de Neuquén en abril de 2018).

Tanto APCA como la Multisectorial Contra la Hidrofractura construyeron, en esa coyuntura, un corpus de información relevante respecto del fracking, y alertaron con respecto a la temática de las explotaciones no convencionales. Se tornaron entonces actores centrales en el proceso de definición del fracking como una problemática pública. Estos colectivos realizan un diagnóstico sobre los impactos de la actividad hidrocarburífera y una lectura en términos económicos, sociales, políticos y culturales de las implicancias de sostener la explotación de recursos fósiles como eje central de la actividad económica de la provincia y de la región. Así, proponen una reflexión integral que contempla la diversificación de la matriz productiva y energética, aunando posturas que en un principio aparecían con cierta heterogeneidad. Estos actores son los que pugnaron por ingresar el tema a las agendas mediáticas y políticas, lo que resulta una cuestión de preponderancia para pensar la movilización, la conflictividad, y la irrupción de esta temática en el espacio público.28

En la construcción de ese diagnóstico nos interesa remarcar la confluencia de dos actores que aquí consideramos vitales en la formulación del fracking como un problema social, político, territorial y ambiental, que interpelaba a la sociedad en su conjunto, y que requería la intervención del Estado en sus distintos niveles. Estos actores preexistían a la conformación tanto de APCA como de la Multisectorial. Como bien señala Merlinsky (2013) es raro encontrar en la antesala del conflicto a un grupo, o a un movimiento como un todo organizado. Sin embargo, existían para el caso de Neuquén redes de sociabilidad y proximidad entre los distintos actores que conformaron estos colectivos. En esas redes de interacción preexistente, las experiencias, la información y el conocimiento circuló, se transmitió y permitió la organización al calor del conflicto por los no convencionales. Los dos actores que consideramos fundamentales en la elaboración de diagnósticos y definiciones en torno al fracking son las comunidades mapuches y el Observatorio Petrolero Sur.

Las comunidades mapuches, nucleadas en la Confederación Mapuche de Neuquén ${ }^{29}$, aportaron la experiencia vivida en sus territorios en relación a dos conflictos centrales. El primero en torno a los pasivos ambientales y a la conflictividad existente con respecto a décadas de explotación convencional de hidrocarburos en sus territorios. En esa dirección, un referente de la Confederación Mapuche destacaba: "La explotación tradicional ha dejado un pasivo ambiental, y un desastre ecológico que es impagable, que es irremediable lo que ha dejado, en la mayor reserva que existió de convencional que fue Loma La Lata, vos recorres Loma La Lata y es un... están las comunidades asentadas sobre un lago de combustible, que está a ocho metros de profundidad nada más, esa consecuencia nefasta, trágica para la vida del pueblo mapuche... ha dejado un recuerdo oscuro de la industria en el lugar." (Entrevista $n^{\circ} 2$ realizada por autor a referente de la Confederación Mapuche de Neuquén).

La alerta contra el fracking para los referentes mapuches se conecta con la memoria mediana de lucha contra la contaminación, que atravesó y atraviesa a las comunidades. Los entrevistados hacen continua referencia a la situación de las comunidades Kaxipayiñ y Paynemill, que aparecen como los

$28 \mathrm{Si}$ bien ambas organizaciones poseían reconocimiento social y un fuerte trabajo en distintas comunidades, trabajos de difusión y educativas, con el correr del tiempo su actividad disminuyó en intensidad. En la actualidad la actividad de APCA se centra en la localidad de Allen, y es mantenida por pocos activistas. Integrantes de la Multisectorial en contra de la Fractura Hidráulica han definido a la organización como en una suerte de estado de latencia, pero sensible a todos los eventos que tienen lugar en la cuenca neuquina, además de que las bases de información generadas por el colectivo se han convertido en un recurso a disposición de cualquier ciudadano y organización.

${ }^{29}$ La Confederación Mapuche de Neuquén es la forma de organización que nuclea al pueblo mapuche. Inspirada en la forma de organización que establece el toki (líder) Calfulcurá hacia el 1800, para institucionalizar la organización mapuche frente al Estado argentino. La Confederación está conformada por seis zonales, que nuclean a los distintos lofs de la región. (Entrevis ta $\mathrm{n}^{\circ} 1$ realizada por autor a referente de la Confederación Mapuche Neuquina). 
ejemplos más paradigmáticos de los resultados de la desidia y los inexistentes controles estatales sobre las empresas, y los impactos sobre el territorio. Como indica Cabrera (2015), sobre el territorio de ambas comunidades se emplaza el yacimiento gasífero de Loma La Lata. En la década del '90 el conflicto entre las comunidades y las empresas tomó relevancia mediática, luego de años de extracción de gas del yacimiento. Los efectos perjudiciales de la actividad quedaron al descubierto cuando "integrantes del Lof Kaxipayiñ obtuvieron un líquido inflamable al perforar un pozo cuyo objetivo era obtener agua para consumo.” (Cabrera, 2015). El caso tomó gran relevancia mediática. A pesar de las reiteradas denuncias de las comunidades, en el año 2000 el gobierno de la provincia y de nación prorrogó la concesión a YPF-Repsol hasta el año 2017, siendo esto rechazado por las comunidades, que fueron reprimidas brutalmente. Si bien aquellas obtuvieron una victoria pírrica al lograr el cobro de servidumbre $^{30}$ por el uso de su suelo, continúan sufriendo las consecuencias de la explotación hidrocarburífera y el atropello empresarial y estatal.

La segunda experiencia vivida en el territorio mapuche es aquella que los enfrentó por primera vez a la explotación de hidrocarburos no convencionales mediante la técnica del fracking en la comunidad Gelay Ko. En dicha comunidad la empresa Apache realizó en el año 2011 el primer pozo no convencional a nivel latinoamericano. Este resulta un doloroso antecedente para el pueblo mapuche, así como el más emblemático. La resistencia estuvo encabezada por la logko de la comunidad, Cristina Linkopan. ${ }^{31}$ Para los entrevistados, la muerte de la joven logko, en marzo del año 2013, representa en toda su expresión la lucha de una comunidad contra la actividad petrolera. Su fallecimiento a temprana edad por problemas respiratorios, se inserta indudablemente en una controversia, al ponerse en duda la causa de la complicación en su salud, y abriendo a la posibilidad de que la explotación de hidrocarburos no convencionales pudiera estar vinculada a las afecciones que sufrió la líder mapuche.

Voceros de la Confederación Mapuche observaban la dificultad de realizar estudios en laboratorios privados para determinar la causa del fallecimiento, sumado a que no se realizaban en la comunidad mediciones de contaminación de aire, tierra y suelo. Además, denunciaban que otros integrantes de la misma comunidad sufrían los mismos síntomas respiratorios que la logko, así como también problemas en la piel y malformaciones.

Ambas experiencias se conectan en la tradición de lucha y resistencia territorial mapuche y brindan al diagnóstico colectivo los efectos que la explotación de hidrocarburos, tanto convencionales como no convencionales, tienen sobre el territorio y las poblaciones. En ese diagnóstico, las comunidades reivindican la defensa del territorio mapuche y denuncian la violación a los órdenes constitucionales que deben respetarse para garantizar el desarrollo de la vida comunitaria mapuche. Con estos antecedentes se advierte el rol relevante que tienen las comunidades en la denuncia y problematización de la matriz hidrocarburífera de la provincia.

Por otro lado, el Observatorio Petrolero Sur, conformado en el año 2008 y vinculado a nivel internacional con Oilwatch, contribuyó con aportes sustanciales a la problemática, generando conocimiento, produciendo información y enfatizando en la potencia de la comunicación desde un campo multidisciplinar.

El Observatorio se encuentra conformado por profesionales provenientes del ámbito de la comunicación y de las ciencias políticas principalmente, y orientan sus trabajos a realizar un diagnóstico sobre la situación hidrocarburífera y energética en general. Desde esta organización se produjo un saber experto, estimulado desde abajo, que confrontó fuertemente con otros saberes expertos hegemónicos que omitían los efectos perniciosos de la producción de energía extrema en los territorios.

\footnotetext{
30 El derecho de servidumbre implica el pago a propietarios, a veces llamados superficiarios, por la ocupación que se hace de sus tierras, por el paso de gasoductos o por las explotaciones petroleras que se encuentran en ellas.

31 La palabra logko, en mapuzungun, designa a la autoridad máxima de un determinado lof (unidad organizacional básica del pueblo mapuche).
} 
La publicación de la revista "Fractura expuesta" en marzo del año 2012, recopilaba los artículos que retomaban la temática del fracking, y fue presentada ante distintos sectores organizados (sindicatos, partidos políticos, comunidades mapuches). En dicha publicación se sistematizaron los debates y controversias con respecto al fracking a nivel mundial, la geopolítica de la resistencia a dicha actividad, y la situación de Argentina y de la provincia de Neuquén en torno a la explotación de no convencionales. Además, en esa publicación se relevaba la situación de la comunidad Kaxipayiñ, y se establecía un diálogo con sectores de la Universidad Nacional del Comahue dedicados a trabajar la temática petrolera. Así, en diálogo con otros expertos, el Observatorio Petrolero Sur puso a disposición, en un lenguaje científico accesible, un conjunto de materiales y producciones que permitieron definir la cuestión del fracking como una problemática ambiental, energética, pero también política, social y de derechos humanos, con el énfasis puesto en los derechos de los pueblos originarios.

\section{La ramificación del conflicto}

Como señalamos previamente, retomamos la mirada de Vaca Muerta como Mega Proyecto, ya que implica pensar los cambios e impactos no sólo en los territorios concretos de extracción del gas y el petróleo, sino también en las otras latitudes afectadas. Esto tiene implicancias al abordar la conflictividad y la descentralización del conflicto en los distintos territorios que colateralmente están implicados en la explotación.

Si bien la organización y movilización de gran parte de sectores de la sociedad disminuyó luego de la ratificación provincial del convenio YPF-Chevron, el conflicto se ramificó a distintos espacios de la provincia y de la región. Adquirió entonces otras características y se localizó en distintos puntos de la provincia, despertando en casi todos los casos nuevos procesos de organización y movilización colectiva.

El conflicto que presenta continuidad hasta la actualidad es el de los lofs mapuches por la violación de sus derechos territoriales por parte de las empresas y el Estado, que desoyen los convenios internacionales que regulan las actividades extractivas en sus territorios, y establecen mecanismos de consulta. Las violencias y avasallamientos se recrudecieron con el cambio de gobierno nacional en el año 2015, que arribó de la mano de un discurso estigmatizador y con una apuesta fuerte a la militarización de los territorios. La conjugación de estos dos factores tuvo consecuencias inmediatas en la persecución de las comunidades mapuches. Desde los discursos oficiales se comenzó a enunciar al mapuche como un enemigo interno, sobre todo haciendo referencia a grupos radicales como la Resistencia Ancestral Mapuche (RAM). El reverdecer de los discursos racistas contra el pueblo mapuche fue acompañado de represiones a lo largo de la cordillera.

La actividad del fracking desató asimismo un ciclo de conflictividad en el ejido urbano de la ciudad de Neuquén. Los basurales petroleros (COMARSA e INDARSA) ubicados en la periferia de la capital neuquina, sufrieron un aumento exponencial de los desechos a tratar, producto del aumento de la actividad hidrocarburífera. La cuestión de las plantas de tratamiento de desechos es interesante, ya que visibiliza la cuestión petrolera en la ciudad, trayendo aparejado un proceso de organización de los vecinos de las periferias. En octubre del 2014, un gran derrame de crudo de una pileta de INDARSA hizo estallar la problemática. Los diputados Eduardo Benítez y Beatriz Kreitman realizaron una denuncia penal a la compañía, calificando el hecho como un delito ambiental (Álvarez, 2016). Los vecinos, acompañados por la Multisectorial contra la Hidrofractura, comenzaron a organizar encuentros entre los afectados, y charlas informativas para que el tema adquiriera visibilidad mediática y política, conformándose la Comisión Fuera Basureros Petroleros. Entre sus demandas, la Comisión exigía que las plantas de tratamiento dejaran de ingresar desechos, y que frenaran la quema de los mismos, por la alta contaminación del aire que, según los vecinos, les traía aparejadas enfermedades, malestares respiratorios y en la piel. Se exigía conjuntamente el traslado de los basurales fuera de la ciudad. Esta cuestión llegó a la legislatura de la provincia, donde se buscó poner freno al ingreso de 
Juan Acacio y Gabriela Wyczykier, Expectativas públicas y conflictos sociales en torno a los hidrocarburos no convencionales en Argentina: algunos apuntes sobre Vaca Muerta, Izquierdas, 49, abril 2020: 457-477

residuos a las plantas, y el traslado de estas a la localidad de Añelo. En el año 2015 se sancionó el decreto 2263/15 que implicaba un nuevo marco para el tratamiento de residuos provenientes de la actividad hidrocarburífera. En el año 2017 las plantas cerraron sus puertas, dejando de ingresar materiales para el tratamiento. Finalmente, en el 2018 se prohibió totalmente la quema de residuos, hasta que las plantas de la localidad de Añelo se encuentren aptas para dicho trabajo.

La conflictividad se trasladó asimismo hacía áreas naturales protegidas, como es el caso de Auca Mahuida. Como establecen Di Risio y Cabrera (2016) el área es una reserva sobresaliente de diversidad de mamíferos de toda la estepa patagónica. La reserva es extremadamente rica en flora y fauna, y se compone de especies que han desaparecido o son muy raras en otras partes del territorio provincia. La Multisectorial contra la Hidrofractura denunció en el año 2014 los avances en la exploración y explotación petrolera. Para aquél entonces existían once concesiones hidrocarburíferas que afectaban directamente al área. Según el colectivo, la regulación y el control del sector por parte de los trabajadores es imposibilitada por presiones del gobierno y las empresas.

Desde el comienzo del desarrollo de las explotaciones de no convencionales los municipios han tenido un papel protagónico en la sanción de ordenanzas que buscan prohibir la actividad en los ejidos municipales. Este accionar comenzó a realizarse en localidades como Allen, Zapala, y Vista Alegre (Provincia de Neuquén), siguiendo el caso pionero de Cinco Saltos (Provincia de Río Negro). En estos ámbitos se comenzaron a gestar procesos de organización colectiva que decantaron en ordenanzas que prohíben la actividad, en defensa del agua, de la vida, y de las matrices productivas tradicionales, principalmente la fruticultura, en localidades como Allen y Vista Alegre. Afloraron así redes de sociabilidad que conectan las resistencias y las distintas experiencias de los municipios que lograron prohibir la actividad. Un integrante de la Asamblea de Vista Alegre libre de fracking aludía en este sentido:

\footnotetext{
"Empezamos a entender geográficamente cual era la composición, entonces empezamos a ver otras asociaciones que estaban en lucha con el mismo tema, y entramos en contacto con la gente de basureros petroleros. Y la problemática que tenía, entonces ahí comprendimos la complejidad de este conflicto. Porque no solamente es contaminar el agua y la tierra, sino también el aire, la población cercana a los basureros empezaron a encontrarse muchos casos de alergias, de reacciones en la piel, respiratorias". (Entrevista $n^{\circ} 3$ realizada por autor a integrante de Vista Alegre libre de fracking y en defensa de la vida en abril de 2018).
}

Para los municipios, la sanción de ordenanzas permitió dar una sutura temporal a la problemática, cuestión que se reactivó al establecerse una contradicción entre la potestad de los municipios por legislar sobre la salud y el ambiente, y la potestad de la provincia sobre los recursos hidrocarburíferos. En apelación a ello, tanto las provincias de Neuquén como de Rio Negro han comenzado a declarar inconstitucionales dichas ordenanzas.

\section{Algunas palabras de cierre}

El megaproyecto de Vaca Muerta implica la producción de energía extrema en una etapa societal de relacionamiento con los recursos fósiles donde se han puesto en cuestión, de parte de distintos actores sociales y públicos, los efectos económicos, sociales, ambientales, y territoriales que ello conlleva. El acceso a los hidrocarburos no convencionales situó a la Argentina ante la posibilidad de continuar apostando a una matriz energética sumamente dependiente de estos recursos, pero también de posicionarse geopolíticamente como un actor de centralidad poco discutible como proveedor de gas y petróleo conforme a las proyecciones gubernamentales y del sector privado. La mercantilización de la energía ha sido potenciada y el destino productivo de la nación continúa ligado a las riquezas de la tierra. 
Este megaproyecto supone, en consecuencia, un conjunto de aristas que ponen de relieve el análisis sociopolítico de este proceso. En esta dirección, aquí hemos introducido apreciaciones sobre las expectativas y condiciones públicas que caracterizan la producción de energía extrema que habilita la formación geológica ubicada en La Patagonia norte, las controversias existentes en torno a la técnica privilegiada para la extracción de no convencionales, y las resistencias sociales y colectivas que se han dinamizado como efecto del aumento de los yacimientos puestos en actividad.

Con ello hemos marcado diversos frentes de conflicto en distintos territorios: comunidades mapuches, áreas naturales protegidas, y el suelo urbano. La actividad hidrocarburífera no convencional convulsiona los espacios sobre los que se asienta, despertando procesos de movilización y organización de distinto tipo. Estas resistencias no emergen con el cambio de gobierno en 2015 sino por el contrario, cuentan con antecedentes incluso prexistentes al momento de inicio de la explotación masiva de estos recursos. Como destacamos en lo que refiere a Vaca Muerta, el gobierno kirchnerista y el de Cambiemos muestra sustantivas continuidades, aunque también presentan algunas diferencias de relevancia. Entre ellas, la profundización de un proceso de mercantilización de la energía y del corrimiento del Estado en lo que refiere a la asignación de subsidios para morigerar el precio en el consumo. Sin embargo y en lo que refiere al megaproyecto Vaca Muerta, las erogaciones públicas continúan direccionándose hacia la valorización de la extracción de no convencionales y de inversión en infraestructura para alentar las inversiones privadas en la actividad. La reforma de aspectos claves del convenio colectivo de trabajo de los petroleros también operó en esta dirección.

Otro aspecto distintivo que afecta directamente a los territorios se advierte concomitantemente durante la nueva fase política que se inició a fines del año 2015, y es la profundización pública de estigmatizaciones raciales hacia los pueblos originarios en la Patagonia, ligado a un aumento de la intervención armada.

En los últimos tiempos, asimismo, el conflicto contra el fracking se ha extendido geográficamente de la mano de la voracidad hidrocarburífera, y en la provincia de Mendoza se han advertido conflictos socioambientales ligados a este proceso. Además, se han desatado allí con velocidad procesos de criminalización y judicialización de los actores movilizados. Las acciones colectivas reflotan entonces la acumulación de luchas en defensa del agua y de la vida, traccionando no sólo la experiencia de Neuquén y de sus espacios organizados, sino además tendiendo puentes con otras luchas ambientales, como respecto de la megaminería. Las masivas puebladas y la consiguiente movilización, mostrarán la capacidad de la sociedad en su conjunto para afrontar el ingreso de la actividad a una provincia con fuerte conciencia en torno a la utilización y el cuidado del agua. Resta ver el camino que adquirirá el proceso organizativo en dicho caso.

\section{Bibliografía:}

Alberto Acosta, "Extractivismo y neoextractivismo: Dos caras de la misma maldición", 2012, disponible en: http://www.polodemocratico.co/pdf/Alberto\%20Acosta.pdf

Pablo Bertinat “Ciudades y energía. Una relación compleja”, Voces en Fénix, año 6 N 47, agosto 2015, pág 30-38, disponible en http://www.vocesenelfenix.com/sites/default/files/numero_pdf/fenix47\%20baja.pdf

Juan Grigera y Laura Álvarez "Extractivismo y acumulación por desposesión. Un análisis de las explicaciones sobre agronegocios, megaminería y territorio en la Argentina de la posconvertibilidad.". Theomai 27-28, 2013. 
Martín Álvarez Mullally, Lisandro Arelovich, Fernando Cabrera, Diego di Risio, Megaproyecto Vaca Muerta: informe de externalidades, EJES, OPSUR, Taller Ecologistas, 2017, disponible en http://ejes.org.ar/InformeExternalidades.pdf

Martin Álvarez Mullally, "Basureros petroleros: cuando el remedio es peor que la enfermedad", en Hernán Scandizzo (ed) La Tentación de Esquisto. Capitalismo, democracia y ambiente en la Argentina no convencional, 1 a ed. Ciudad Autónoma de Buenos Aires, Ediciones del Jinete Insomne, 2016, pág. 135139.

Martín Álvarez Mullally y Felipe Gutiérrez, "Los que dicen: no", en Hernán Scandizzo (Ed), La Tentación de Esquisto. Capitalismo, democracia y ambiente en la Argentina convencional.1 a ed. Ciudad Autónoma de Buenos Aires: Ediciones del Jinete Insomne, 2016, pág. 107-113.

Tatiana Roa Avedaño y Hernán Scandizzo, "Qué entendemos por energía extrema”, en Extremas. Nuevas fronteras del extractivismo energético en Latinoamérica, Oilwatch Latinoamérica, disponible en http://www.opsur.org.ar/blog/wp-content/uploads/2017/05/2017-boletin-Extrema.pdf , 2017, pág. $5-9$.

Fernando Cabrera, La violencia petrolera, 2015, Disponible en: http://www.opsur.org.ar/blog/2015/11/06/la-violencia-petrolera/

Concerned Health Professionals of NY, Heinrich Boll Stiftung, Physicians for Social Responsibility, Compendio de hallazgos científicos, médicos y de medios de comunicación que demuestran los riesgos y daños del Fracking (extracción no convencional de gas y petróleo), tercera edición, octubre 2015, disponible en https://mx.boell.org/sites/default/files/compendium final 25 de mayo.pdf

Eduardo D Elía y Observatorio Petrolero Sur, “A nivel global, ¿cuál ha sido el rol de las empresas petroleras respecto a los yacimientos no convencionales? ¿Y el de Estados Unidos?", en 20 mitos y realidades sobre sobre el fracking, Buenos Aires, Editorial El Colectivo, 2014, pág. 29 -38.

Nicolás Di Sbroiavaca, Shale oil y shale gas en la Argentina. Estado de situación y prospectiva. Documento de trabajo-agosto, Argentina, Fundación Bariloche, 2013.

Diego Di Risio. Y Fernando Cabrera, “Auca Mahuida: Área Protegida para el Sacrificio. en Hernán Scandizzo (ed.) La Tentación de Esquisto. Capitalismo, democracia y ambiente en la Argentina no convencional”, 1 a ed. Ciudad Autónoma de Buenos Aires, Ediciones del Jinete Insomne, 2016, pág. 95-101.

Fundación Ambiente y Recursos Naturales, "Los subsidios a los combustibles fósiles en Argentina 2017-2018", documento de trabajo mayo 2018, disponible en https://www.greenpeace.org/argentina/Global/argentina/2018/06/DOC_COMBUSTIBLES_final.p df

Ernesto Gallegos, “Todo lo que hay que saber sobre fracking”, U238. Tecnología Industrial con desarrollo, 2018, Disponible en: http://u-238.com.ar/todo-lo-que-hay-que-saber-sobre-fracking/

Gustavo García Zanotti, Marcos Kofman, Facundo López Crespo, y Jorge Chemes, Ganadores y perdedores en la Argentina de los hidrocarburos no convencionales, EJES, OPSUR, Taller Ecologistas, 2017, disponible en http://www.psocialista.org/ejes-ganadores-perdedores-la-argentina-loshidrocarburos-no-convencionales/ 
Salvador Gil, Pablo Govorani y Luciano Codeseira, El gas natural en la Argentina. Propuestas. Período 2016-2025, Cámara Argentina de la Construcción, 2015, disponible en https://www.researchgate.net/profile/Salvador Gil2/publication/314100403 Area de Pensamiento Estrategico_Preparado_para_la_Camara_Argentina de la_Construccion/links/58b57ddd92851ca13e5 2cba7/Area-de-Pensamiento-Estrategico-Preparado-para-la-Camara-Argentina-de-la-Construccion.pdf Adriana Giuliani, "La explotación de Vaca Muerta (Argentina) y la governance internacional”, ponencia presentada en el II Congreso Internacional de Administración de Negocios Internacionales, Colombia, septiembre 2017, disponible en https://www.researchgate.net/publication/320623625_LA_EXPLOTACION_DE_LA_VACA_MUE RTA ARGENTINA Y LA GOVERNANCE INTERNACIONAL

Evelyn Goldstein, Matías Kulfas, Diego Margulis y Guido Zack "El déficit del sector energético en la Argentina y sus efectos macroeconómicos (2003-2014)", en Revista Realidad Económica No 298, 2016, Buenos Aires: Instituto Argentino para el Desarrollo Económico.

David Gómez Jiménez, Jorge Sans Oliva, y Jaime Portero Larragueta, Hidrocarburos no convencionales y sus implicaciones, 2014, disponible en http://www.energyoutofthebox.com/hidrocarburos-no-convencionales-en-eeuu-y-sus-implicaciones/

Gerardo Honty y Eduardo Gudynas, Cambio Climático y Transiciones al Buen Vivir-Alternativas al desarrollo para un clima seguro. Lima, CLAES y RedGE, 2014.

Instituto Argentino del Petróleo y el Gas, Aspectos técnicos, estratégicos y económicos del transporte y la distribución del gas. Buenos Aires, IAPG, 2014.

Gabriela Merlinsky, La espiral del conflicto. Una propuesta metodológica para realizar estudios de caso en el análisis de conflictos ambientales. En Cartografias del conflicto ambiental en Argentina; Gabriela Merlinsky (Ed) Ciudad Autónoma de Buenos Aires, Fundación CICCUS, 2013, pág. 61-89.

Observatorio Petrolero Sur, "Vaca Muerta, un megaproyecto que se extiende", 2017, Disponible en: http://www.opsur.org.ar/blog/2017/04/25/el-megaproyecto-vaca-muerta-una-propuesta-de-

intervencion/

Silvina Peco, "Producción de petróleo y gas aumentó muy poco en 2018", 2019, disponible en https://www.ambito.com/produccion-petroleo-y-gas-avanzo-muy-poco-2018-n5009403

Sebastián Penelli, "Argentina, lejos del autoabastecimiento energético: se importa más crudo y bajan la producción y las regalías". 2018, disponible en: http://www.ambito.com/910808-argentina-lejos-delautoabastecimiento-energetico-se-importa-mas-crudo-y-bajan-la-produccion-y-las-regalias

Lorena Riffo, Hidrocarburos, fracking y resistencias sociales. Un análisis social de las políticas hidrocarburíferas contemporáneas en Argentina desde la provincia de Neuquén. En Actuel Marx Intervenciones $n^{\circ}$ 20. Santiago, Ediciones LOM, 2016.

Alejandro Rebossio, "Vaca Muerta: quiénes son los dueños del yacimiento", 2015, Disponible en: https://www.lanacion.com.ar/1785554-vaca-muerta-quienes-son-los-duenos-del-yacimiento

Hernán Scandizzo, "Hidrocarburos y diversificación productiva en tiempos de Vaca Muerta. Nueva expansión de frontera del capital”, en Perez Roig, Scandizzo, di Risio (comps) Vaca Muerta. Construcción de una estrategia. Buenos Aires, Ediciones Jinete Insomne, 2016, pág. 89-144. 
Santiago, Spaltro, "Vaca Muerta milagrosa: prometen crear 100 mil nuevos empleos en un ano", 2018, disponible en: www.cronista.com/economiapolitica/Vaca-Muerta-milagrosa-prometen-crear-100-milnuevos-empleos-en-un-ano-20180917-0088.html

Maristella Svampa, "Frackinstein. Vaca Muerta, entre la inviabilidad ambiental y el pluriblindaje", en El cohete a la Luna, disponible en https://www.elcohetealaluna.com/author/maristella-svampa/

Maristella Svampa, Movimientos sociales y nuevo escenario regional: Las inflexiones del paradigma neoliberal en América Latina (En línea). Sociohistórica, (19-20), 2016, pág. 141-155, Disponible en: http://www.memoria.fahce.unlp.edu.ar/art_revistas/pr.3612/pr.3612.pdf

Maristella Svampa, Debates Latinoamericanos. Indianismo, desarrollo, dependencia y populismo, Buenos Aires, Edhasa, 2016.

Maristella Svampa y Observatorio Petrolero Sur, “¿Desarrollo o maldesarrollo? ¿Qué tipos de sociedades locales se van generando al compás de la expansión de la actividad hidrocarburífera a gran escala?", en 20 mitos y realidades sobre sobre el fracking, Buenos Aires, Editorial El Colectivo, 2014, pág. $131-146$.

Claudia Viale y Edgardo Cruzado, La distribución de la renta de las industrias extractivas a los gobiernos subnacionales en América Latina, RevenueWatch, 2012, disponible en https://resourcegovernance.org/sites/default/files/Revenuedistribution-Spanish.pdf

\section{Fuentes:}

Conclusiones de la "Jornada de capacitación y asamblea resolutiva de vecinos y organizaciones ante la grave crisis ambiental en las cuencas de la región norpatagónica”. Allen, Rio Negro, 27 de octubre 2012. Disponible en https://www.facebook.com/arturo.cavallo.productor/posts/430626520330112? tn $=\mathrm{K}$ -

Declaraciones de Miguel Galuccio. 2 de diciembre de 2014. Disponible en: https://www.minutouno.com/notas/345983-galuccio-desestimo-que-la-baja-el-precio-del-petroleoafecte-vaca-muerta

Discurso del presidente Mauricio Macri. Lunes 23 de abril de 2018. Disponible en: https://www.casarosada.gob.ar/informacion/discursos/42566-el-presidente-mauricio-macri-visitovaca-muerta 